\title{
Natural phytochemicals as testable therapeutic alternatives for HER-2-enriched breast cancer (Review)
}

\author{
NITIN TELANG \\ Cancer Prevention Research Program, Palindrome Liaisons Consultants, Montvale, NJ 07645-1559, USA
}

Received May 14, 2020; Accepted July 15, 2020

DOI: $10.3892 /$ wasj.2020.60

\begin{abstract}
The human epidermal growth factor receptor-2 (HER-2)-enriched molecular subtype of breast cancer responds to HER-2 targeted and/or to endocrine therapy, depending on the presence of functional hormone receptors. These long-term therapeutic options are associated with systemic toxicity and acquired drug resistance. Resistance to conventional and targeted chemo-endocrine therapy leads to the emergence of drug-resistant cancer stem cells that promote therapy-resistant disease progression. Relatively non-toxic natural phytochemicals may provide testable alternatives to therapy-resistant breast cancer. The present review summarizes data on the following: i) Growth inhibitory efficacy of mechanistically distinct natural phytochemicals in a preclinical model for HER-2-enriched breast cancer; ii) drug-resistant stem cell model for HER-2-enriched breast cancer; and iii) proof of concept for efficacy of natural phytochemicals as testable alternatives against drug-resistant cancer stem cells. Relative to the non-tumorigenic human mammary epithelial 184-B5 cells, HER-2 expressing tumorigenic 184-B5/HER cells (HER-2-enriched breast cancer model) exhibit hyper-proliferation and increased anchorage independent colony formation. Resistance to lapatinib, a small molecule inhibitor of EGFR and HER-2, provides the LAP-R phenotype that exhibits increased tumor spheroid formation and an upregulated expression of the stem cell markers, CD44, NANOG and OCT-4. Select bioactive natural phytochemicals, such as cruciferous glucosinolate, tea polyphenol, soy isoflavone and rosemary terpenoid at their respective maximum cytostatic concentrations exert anti-proliferative and pro-apoptotic effects on parental 184-B5/HER cells and downregulate the phosphorylation of HER-2. The expression of stem cell markers in the LAP-R phenotype is effectively inhibited by a bioactive terpenoid. Collectively, these data
\end{abstract}

Correspondence to: Professor Nitin Telang, Cancer Prevention Research Program, Palindrome Liaisons Consultants, 10 Rolling Ridge Road, Suite B, Montvale, NJ 07645-1559, USA

E-mail: ntelang3@gmail.com

Key words: HER-2-enriched breast cancer, drug resistance, stem cells, natural phytochemicals, growth inhibition, apoptosis validate an experimental approach to identify efficacious natural phytochemicals as testable therapeutic alternatives for chemo-endocrine therapy resistant breast cancer.

\section{Contents}

1. Introduction

2. Cellular models

3. Natural phytochemicals

4. Status of hyper-proliferation

5. Growth inhibitory efficacy of natural phytochemicals

6. Drug-resistant stem cell model

7. Stem cell targeting testable alternatives

8. Conclusions and future prospects

\section{Introduction}

Global gene expression profiling of clinical breast cancer has provided molecular classification of subtypes based of differential expression of genes for hormone and growth factor receptors (1). This molecular classification dictates specific conventional chemo-endocrine therapy or pathway selective small molecule inhibitor based targeted therapy. Thus, for the hormone receptor-positive/human epidermal growth factor receptor-2 (HER-2)-positive luminal B molecular subtype, treatment with selective estrogen receptor modulators, aromatase inhibitors and HER-2 inhibitors represent common options (2). By contrast, for the hormone receptor-negative/HER-2-positive HER-2 enriched subtype HER-2-targeted therapy represents a viable option (3).

Long-term treatment with conventional and/or targeted therapy is frequently associated with systemic toxicity and acquired tumor resistance that collectively compromise patient compliance and favor therapy-resistant tumor progression predominantly due to the emergence of drug-resistant cancer stem cells (4).

In preclinical investigations, human breast carcinomaderived BT474, MDA-MB-361 and MCF-7/HER cell models for the luminal B subtype, and SKBr-3 and MDA-MB-435 cell models for the HER-2-enriched subtype $(5,6)$, represent valuable experimental systems with which to elucidate the mechanisms of drug resistance and for the identification of efficacious lead compounds. Multiple drug resistance via 
acquired resistance to HER-2/EGFR-selective small molecule inhibitors in the HER-2-enriched model (3) or cross-resistance to aromatase inhibitors in the MCF- $7^{\mathrm{AROM}}$ model $(7,8)$ represent additional approaches. Recent advances in the development of human cancer models include genetically engineered mouse models and constituent cells lines, patient-derived xenografts and constituent organoid models, and drug-resistant cancer stem cell models. Collectively, these approaches promise the clinical translation of preclinical data.

Acquired drug resistance leads to the lack of a response to conventional and/or targeted chemo-endocrine therapy, and is frequently is associated with therapy-resistant cancer stem cells that are characterized by pluripotency, tumor-initiating potential and the upregulated expression of several cell surface proteins and nuclear transcriptional factors (9).

The limitations of chemo-endocrine and/or targeted therapy emphasize an unmet need to develop clinically relevant cancer stem cell models and identify efficacious testable alternatives for stem cell targeted therapy of chemo-endocrine therapy resistant breast cancer.

The present review summarizes a comparison of recently generated unpublished data with that from previously published data on the following: i) Growth inhibitory efficacy of mechanistically distinct natural phytochemicals on a cellular model for the HER-2-enriched breast cancer subtype; ii) drug-resistant stem cell model for HER-2-enriched breast cancer; and iii) proof of concept for efficacy of natural phytochemicals as testable alternatives for drug resistant breast cancer stem cells.

\section{Cellular models}

The human tissue-derived cellular models included in the present review are distinct from those established human breast carcinoma-derived cell lines as models for the HER-2-enriched breast cancer subtype. In the present 184-B5/HER model, non-tumorigenic human mammary epithelial cells (10) stably transfected with HER-2 oncogene exhibit tumorigenic transformation due to the overexpression of the HER-2 oncogene (11).

Cell lines in experimental models. The following cell lines represent the experimental models: i) 184-B5: This cell line was established from a histologically normal reduction mammoplasty sample. These cells lack the expression of ER, PR and HER-2 and are non-tumorigenic (10). These cells represent a baseline control for investigations on 184-B5/HER and Lapatinib resistant (LAP-R) models. ii) 184-B5/HER: This cell line over-expresses HER-2 oncogene. The cells are ER/PR negative and HER-2 positive, and produce tumors on in vivo transplantation (11). iii) 184-B5/HER (LAP-R): These cells are resistant to lapatinib, a small molecule inhibitor of EGFR and HER-2. These cells exhibit the downregulated expression of p-EGFR and p-HER-2, and the upregulated expression of several stem cell specific cellular and molecular markers (12).

Quantitative end point biomarkers. The quantitative parameters include population doubling times, saturation density, as monitored by viable cell number using trypan blue dye exclusion assay. Cell cycle progression and cellular apoptosis are monitored by flow cytometry and presented as the
$\mathrm{G}_{1}: \mathrm{S}+\mathrm{G}_{2} / \mathrm{M}$ ratio and the sub- $\mathrm{G}_{0}$ phase. The expression levels of select cell cycle regulatory and apoptosis-specific proteins are monitored by flow cytometry-based quantitative immunofluorescence assay that involves the sorting of cells positive for FITC-conjugated antibody (13). The fluorescence data are expressed as log mean fluorescent units (FU) per $10^{4}$ fluorescent events following normalization by FU of cells stained with FITC-IgG antibody.

The statistically significant differences between the control and treatment groups were analyzed using a two sample Student's t-test, one-way ANOVA and Dunnett's post hoc multiple comparisons test with a threshold of $\alpha=0.05$, and the Chi square test where appropriate.

\section{Natural phytochemicals}

These agents are selected based on their documented chemo-preventive efficacy in preclinical models of epithelial organ site cancers. To ascertain the feasibility of the experimental approach, select phytochemicals, such as cruciferous glucosinolate indole-3-carbinol (I3C), tea polyphenol epigallocatechin gallate (EGCG), soy isoflavone genistein (GEN) and rosemary terpenoids carnosic acid (CA) and carnosol (CSOL), are tested on the non-tumorigenic 184-B5 cells. Subsequently these agents are tested for their growth inhibitory efficacy on the 184-B5/HER model. Compared to the 184-B5 model, the 184-B5/HER model exhibits substantially greater growth inhibitory efficacy. At the mechanistic levels, I3C alters the cellular metabolism of estradiol to generate the anti-proliferative metabolite 2-hydroxyestrone (14). EGCG and GEN inhibit the expression of proliferative cell nuclear antigen (PCNA) and cyclin D1, and increase the expression of the cyclin-dependent kinase inhibitor (CDKI) p16 ${ }^{\mathrm{INK} 4}$ (15). CA and CSOL inhibit tyrosine kinase expression and upregulate p16 $6^{\mathrm{INK} 4}$ expression (15), induce cytostatic $\mathrm{G}_{2} / \mathrm{M}$ arrest and accumulate $\mathrm{G}_{2}$-specific cyclin B1 (16). CSOL also inhibits the expression of inducible cyclo-oxygenase-2 (COX-2) via the protein kinase $\mathrm{C} /$ mitogen-activated protein kinase (PKC/MAPK) pathway (17).

\section{Status of hyper-proliferation}

The data on the status of hyper-proliferation in 184-B5/ HER model are summarized in Table I. In comparison with the non-tumorigenic 184-B5 cells, the hyper-proliferative 184-B5/HER cells exhibit an approximately 55\% reduction in population doubling times, an approximately $63 \%$ increase in saturation density, an approximately $96 \%$ reduction in the sub- $\mathrm{G}_{0}$ (apoptotic) population and a substantial increase in anchorage-independent colony formation, the latter being an established in vitro surrogate end point for in vivo tumor development (16). In addition, the 184-B5/HER cells exhibit an approximately 178-fold increase in HER-2 expression and an approximately 231-fold increase in pHER-2 expression.

\section{Growth inhibitory efficacy of natural phytochemicals}

The data on the growth inhibitory efficacy of natural phytochemicals is summarized in Table II. Treatment with individual phytochemicals at their respective maximum 
Table I. Hyper-proliferation in the HER-2-enriched 184-B5/HER model.

Cell line

\begin{tabular}{|c|c|c|c|c|}
\hline \multirow[b]{2}{*}{ Quantitative end point } & \\
\hline & $184-\mathrm{B5}^{\mathrm{a}}$ & 184-B5/HER ${ }^{\mathrm{a}}$ & P-value & Relative to $184-\mathrm{B} 5$ \\
\hline Population doubling $(\mathrm{h})^{\mathrm{b}}$ & $34.1 \pm 1.7$ & $15.3 \pm 4.1$ & 0.04 & $-55.1 \%$ \\
\hline Saturation density $\left(\mathrm{x} 10^{5}\right)^{\mathrm{b}}$ & $23.7 \pm 1.3$ & $38.6 \pm 1.7$ & 0.02 & $+62.9 \%$ \\
\hline $\mathrm{G}_{1}: \mathrm{S}+\mathrm{G}_{2} / \mathrm{M}(\text { ratio })^{\mathrm{c}}$ & $1.8 \pm 0.3$ & $0.8 \pm 0.2$ & 0.04 & $-55.6 \%$ \\
\hline Sub-G $\mathrm{G}_{0}(\%)^{\mathrm{c}}$ & $18.9 \pm 2.6$ & $0.7 \pm 0.2$ & 0.01 & $-96.3 \%$ \\
\hline \multicolumn{5}{|l|}{ Anchorage-independent } \\
\hline Colony number (per 100 cells) ${ }^{\mathrm{d}}$ & Undetected & $25.8 \pm 4.7$ & & \\
\hline HER-2 (log mean FU) ${ }^{c}$ & $0.3 \pm 0.1$ & $53.8 \pm 2.5$ & 0.005 & $+178 \mathrm{X}$ \\
\hline p-HER-2 $(\log \text { mean FU })^{\mathrm{c}}$ & $0.2 \pm 0.1$ & $46.5 \pm 2.2$ & 0.005 & $+231 X$ \\
\hline
\end{tabular}

Table II. Anti-proliferative effects of natural phytochemicals in 184-B5/HER cells.

\begin{tabular}{|c|c|c|c|c|c|c|c|}
\hline \multirow[b]{2}{*}{ Treatment } & \multirow[b]{2}{*}{ Concentration $(\mu \mathrm{M})^{\mathrm{a}}$} & \multicolumn{6}{|c|}{ Biomarker } \\
\hline & & $\mathrm{G}_{1}: \mathrm{S}+\mathrm{G}_{2} / \mathrm{M}^{\mathrm{b}}$ & P-value & $\delta \mathrm{EtOH}$ & p-HER-2 ${ }^{c}$ & P-value & $\delta \mathrm{EtOH}$ \\
\hline $\mathrm{EtOH}$ & $0.1 \%$ & $0.7 \pm 0.1$ & & - & $46.5 \pm 3.3$ & & - \\
\hline $\mathrm{I} 3 \mathrm{C}$ & 100 & $1.7 \pm 0.2$ & 0.02 & $+1.4 \mathrm{X}$ & $34.4 \pm 5.6$ & 0.05 & $-26.0 \%$ \\
\hline EGCG & 20 & $1.5 \pm 0.2$ & 0.02 & $+1.1 \mathrm{X}$ & $18.7 \pm 0.9$ & 0.02 & $-59.8 \%$ \\
\hline GEN & 10 & $2.9 \pm 0.4$ & 0.01 & $+3.1 \mathrm{X}$ & $6.9 \pm 0.3$ & 0.01 & $-85.2 \%$ \\
\hline $\mathrm{CA}$ & 10 & $1.0 \pm 0.1$ & & $+42.8 \%$ & $37.1 \pm 1.7$ & 0.05 & $-20.2 \%$ \\
\hline CSOL & 10 & $1.0 \pm 0.1$ & & $+42.8 \%$ & $36.0 \pm 1.6$ & 0.05 & $-22.6 \%$ \\
\hline
\end{tabular}

${ }^{\mathrm{a}} \mathrm{IC}_{90}$, maximum cytostatic. ${ }^{\mathrm{b}}$ Determined by FACS analysis of PI-positive cells. ${ }^{\mathrm{D}}$ Determined by immunofluorescence assay using FACS analysis of FITC-conjugated antibody positive cells. Mean $\pm \mathrm{SD}, \mathrm{n}=3$ per treatment group. Data were analyzed by ANOVA and Dunnett's post-hoc multiple comparison test $(\alpha=0.05)$. FACS, fluorescence assisted cell sorting; PI, propidium iodide; FITC, fluorescence isothiocyanate; EtOH, ethanol (solvent control); p-HER-2, phosphorylated HER-2, I3C, indole-3-carbinol; EGCG, epigallocatechin gallate; GEN, genistein; CA, carnosic acid; CSOL, carnosol, $\mathrm{X}$, fold.

cytostatic $\left(\mathrm{IC}_{90}\right)$ concentrations resulted in a substantial increase in the $\mathrm{G}_{1}: \mathrm{S}+\mathrm{G}_{2} / \mathrm{M}$ ratio ranging from approximately $43 \%$ for CA to approximately 3 -fold for GEN. This increase in the $\mathrm{G}_{1}: \mathrm{S}+\mathrm{G}_{2} / \mathrm{M}$ ratio is indicative of cytostatic growth arrest. At the mechanistic level, phytochemical treatment resulted in the downregulated expression of p-HER-2, ranging from approximately $20 \%$ for CA to approximately $85 \%$ for GEN. In addition, these data facilitate the rank ordering of natural phytochemicals based on their efficacy for biomarker modulation. Thus, with regard to the $\mathrm{G}_{1}: \mathrm{S}+\mathrm{G}_{2} / \mathrm{M}$ ratio, the rank order is $\mathrm{GEN}>\mathrm{I} 3 \mathrm{C}>\mathrm{EGCG}>\mathrm{CA}=\mathrm{CSOL}$. For pHER-2 inhibition the rank order is GEN $>$ EGCG $>\mathrm{I} 3 \mathrm{C}>\mathrm{CSOL}>\mathrm{CA}$. Thus, the rank order suggests distinct efficacy for p-HER-2 inhibition that may be responsible for the observed effect on cell cycle progression.

The data on the pro-apoptotic effects of the phytochemicals are summarized in Table III. Treatment with the phytochemicals results in a substantial increase of the cell population in the sub- $\mathrm{G}_{0}$ (apoptotic) phase of the cell cycle ranging from approximately 8 -fold for I3C to approximately 17 -fold for GEN, relative to the solvent control. At the mechanistic level, the induction of cellular apoptosis was associated with a reciprocal modulation of apoptotic-specific proteins due to the reduced expression of the anti-apoptotic BCL-2 protein, ranging from approximately $23 \%$ for I3C to approximately $67 \%$ for $\mathrm{GEN}$, and the increased expression of pro-apoptotic BAX protein, ranging from approximately $23 \%$ for I3C to approximately $76 \%$ for CSOL (Table IV). Thus, with regard to the induction of apoptosis, the rank order is $\mathrm{GEN}>\mathrm{CSOL}>\mathrm{EGCG}>\mathrm{CA}>\mathrm{I} 3 \mathrm{C}$. The rank order for the decrease in BCL-2 expression is $\mathrm{GEN}>\mathrm{CSOL}>\mathrm{CA}>\mathrm{EGCG}>\mathrm{I} 3 \mathrm{C}$, while the rank order for the increase in BAX expression is $\mathrm{CSOL}>\mathrm{GEN}>\mathrm{CA}>\mathrm{EGCG}>\mathrm{I} 3 \mathrm{C}$. Collectively, the rank order for the efficacy for induction of cellular apoptosis indicates distinct mechanisms of action for 
Table III. Pro-apoptotic effects of natural phytochemicals in 184-B5/HER cells.

Biomarker

\begin{tabular}{lcccr}
\cline { 3 - 4 } Treatment & Concentration $(\mu \mathrm{M})^{\mathrm{a}}$ & Sub-G $_{0}(\%)^{\mathrm{b}}$ & P-value & SEtOH \\
\hline EtOH & $0.1 \%$ & $0.7 \pm 0.2$ & & $+8.1 \mathrm{X}$ \\
I3C & 100 & $6.4 \pm 1.8$ & 0.02 & $+10.6 \mathrm{X}$ \\
EGCG & 20 & $8.1 \pm 2.3$ & 0.01 & $+17.1 \mathrm{X}$ \\
GEN & 10 & $12.7 \pm 3.6$ & 0.01 & $+9.3 \mathrm{X}$ \\
CA & 10 & $7.2 \pm 2.0$ & 0.02 & $+13.8 \mathrm{X}$ \\
CSOL & 10 & $10.4 \pm 2.9$ & 0.01 & . \\
\hline
\end{tabular}

${ }^{\mathrm{a}} \mathrm{IC}_{90}$, maximum cytostatic. ${ }^{\mathrm{b}}$ Determined at day 3 post-seeding by FACS analysis of PI-positive cells. Mean $\pm \mathrm{SD}, \mathrm{n}=3$ per treatment group Data analyzed by ANOVA and Dunnett's post-hoc multiple comparison test $(\alpha=0.05)$. FACS, fluorescence-assisted cell sorting, EtOH, ethanol (solvent control); I3C, indole-3-carbinol; EGCG, epigallocatechin gallate; GEN, genistein; CA, carnosic acid; CSOL, carnosol; BCL-2, B-cell lymphoma; BAX, BCL-2-associated X protein, X, fold change.

Table IV. Modulation of apoptosis associated protein by natural phytochemicals in 184-B5/HER cells.

\begin{tabular}{|c|c|c|c|c|c|c|c|}
\hline \multirow[b]{2}{*}{ Treatment } & \multirow[b]{2}{*}{ Concentration $(\mu \mathrm{M})^{\mathrm{a}}$} & \multicolumn{6}{|c|}{ Biomarker } \\
\hline & & BCL-2 $2^{\mathrm{b}}$ & P-value & $\delta \mathrm{EtOH}$ & $\mathrm{BAX}^{\mathrm{b}}$ & P-value & $\delta \mathrm{EtOH}$ \\
\hline $\mathrm{EtOH}$ & $0.1 \%$ & $80.5 \pm 5.1$ & & - & $25.3 \pm 2.7$ & & - \\
\hline $\mathrm{I} 3 \mathrm{C}$ & 100 & $62.1 \pm 3.9$ & 0.05 & $-22.8 \%$ & $32.6 \pm 3.3$ & 0.05 & $+22.8 \%$ \\
\hline EGCG & 20 & $51.0 \pm 3.2$ & 0.05 & $-36.6 \%$ & $35.2 \pm 3.6$ & 0.04 & $+39.1 \%$ \\
\hline GEN & 10 & $26.7 \pm 1.7$ & 0.01 & $-66.8 \%$ & $44.1 \pm 4.5$ & 0.01 & $+74.3 \%$ \\
\hline $\mathrm{CA}$ & 10 & $31.5 \pm 1.9$ & 0.02 & $-60.9 \%$ & $37.5 \pm 3.8$ & 0.04 & $+48.2 \%$ \\
\hline CSOL & 10 & $29.9 \pm 1.9$ & 0.02 & $-62.8 \%$ & $44.5 \pm 4.5$ & 0.01 & $+75.9 \%$ \\
\hline
\end{tabular}

${ }^{a} \mathrm{IC}_{90}$, maximum cytostatic. ${ }^{b}$ Determined at day 3 post-seeding by FACS analysis of FITC-conjugated antibody-positive cells. Mean \pm SD, $\mathrm{n}=3$ per treatment group. Data are presented as log mean FU per $10^{4}$ fluorescent events, and analyzed by ANOVA and Dunnett's post-hoc multiple comparison test $(\alpha=0.05)$. BCL-2, B-cell lymphoma; BAX, BCL-2 associated X protein; EtOH, ethanol (solvent control); I3C, indole-3-carbinol; EGCG, epigallocatechin gallate; GEN, genistein; CA, carnosic acid; CSOL, carnosol.

individual phytochemical. It is also notable that the growth inhibitory effects of these phytochemicals have been reported in the HER-2-negative human breast carcinoma derived cell lines, MCF-7, MCF-10 CA 1a and MDA-MB-231 (18-21). However, the effective concentrations differ from the ones presented for the 184-B5/HER model.

\section{Drug-resistant stem cell model}

In the preclinical models for HER-2-enriched breast cancer, the HER-2-specific antibody, trastuzumab, and the HER-2/EGFR dual-specific small molecule inhibitors display acquired drug resistance $(22,23)$. Consistent with these data, the 184-B5/HER cells treated with the HER-2/EGFR small molecule inhibitor, lapatinib (LAP), provided the drug-resistant stem cell model. Long-term treatment with the maximum cytostatic $\left(\mathrm{IC}_{90}\right)$ concentration of LAP generated progressively growing LAP-R cells. The data summarized in Table $\mathrm{V}$ demonstrate an approximately 1 -fold increase in the number of tumor spheroids, an approximately 3 -fold increase in cluster of differentiation (CD44), a 3-fold increase in DNA binding homeobox nuclear transcription factor (NANOG) and a 2-fold increase in octamer binding transcription factor-4 (OCT-4), relative to that observed in LAP-sensitive (LAP-S) cells. The cell surface marker, CD44, and the nuclear transcription factors, NANOG and OCT-4, represent well-established markers of the stem cell population (9). Thus collectively, these data indicate that the LAP-R cells may represent putative cancer stem-like cells in the present model.

\section{Stem cell targeting testable alternatives}

Frequent occurrence of acquired tumor resistance against pharmacological therapeutic agents $(2,3,7,8)$ and the emergence of drug-resistant cancer stem cells $(22,23)$ emphasizes an unmet need to identify stem cell targeting testable alternatives. Unlike pharmacological agents, natural phytochemicals, due to their low toxicity profiles, are less likely to induce acquired tumor resistance. Published studies on the rosemary terpenoids, CA and CSOL, have documented potent anti-proliferative and/or pro-apoptotic effects at cytostatic low $\mu \mathrm{M}$ concentrations on the present HER-2-enriched model (16). It is therefore of considerable relevance to examine the stem cell targeted 
Table V. Drug-resistant stem cells derived from the lapatinib-resistant (LAP-R) phenotype.

\begin{tabular}{|c|c|c|c|c|}
\hline \multirow[b]{2}{*}{ Phenotype } & \multicolumn{4}{|c|}{ Expression of stem cell markers } \\
\hline & Tumor spheroids ${ }^{\mathrm{a}}$ & $\mathrm{CD} 44^{\mathrm{b}}$ & $\mathrm{NANOG}^{\mathrm{b}}$ & OCT $-4^{b}$ \\
\hline LAP-S & $4.5 \pm 1.2$ & $4.0 \pm 1.1$ & $2.2 \pm 0.6$ & $4.8 \pm 1.3$ \\
\hline LAP-R & $10.3 \pm 2.7$ & $16.8 \pm 3.6$ & $9.7 \pm 2.5$ & $9.1 \pm 2.4$ \\
\hline$\chi^{2}$ & 7.88 & & & \\
\hline P-value & 0.005 & 0.01 & 0.01 & 0.03 \\
\hline Relative to LAP-S & $+1.3 \mathrm{X}$ & $+3.2 \mathrm{X}$ & $+3.4 \mathrm{X}$ & $+1.8 \mathrm{X}$ \\
\hline
\end{tabular}

Table VI. Modulation of stem cell markers in the lapatinib-resistant (LAP-R) phenotype.

\begin{tabular}{|c|c|c|c|c|c|}
\hline \multirow[b]{2}{*}{ Treatment } & \multirow[b]{2}{*}{ Concentration } & \multicolumn{4}{|c|}{ Expression of stem cell markers } \\
\hline & & Tumor spheroids ${ }^{a}$ & $\mathrm{CD} 44^{\mathrm{b}}$ & $\mathrm{NANOG}^{\mathrm{b}}$ & OCT- $4^{\mathrm{b}}$ \\
\hline DMSO & $0.1 \%$ & $14.8 \pm 1.9$ & $20.8 \pm 4.4$ & $11.8 \pm 3.1$ & $14.2 \pm 3.8$ \\
\hline CSOL & $5 \mu \mathrm{M}$ & $1.9 \pm 0.2$ & $2.9 \pm 0.6$ & $2.7 \pm 0.7$ & $2.9 \pm 0.9$ \\
\hline$\chi^{2}$ & & 7.74 & & & \\
\hline P-value & & 0.010 & 0.010 & 0.020 & 0.020 \\
\hline Relative to DMSO & & $-87.2 \%$ & $-86.0 \%$ & $-77.1 \%$ & $-79.6 \%$ \\
\hline
\end{tabular}

efficacy of natural phytochemicals. The data presented in Table VI demonstrate that in response to a treatment with CSOL the LAP-R cells exhibit an approximately $87 \%$ decrease in the number of tumor spheroids, an $86 \%$ decrease in CD44 expression, a $77 \%$ decrease in NANOG and an $80 \%$ decrease in OCT-4 expression, relative to the solvent-treated controls. Collectively, these data provide a proof of concept for a mechanistic lead for the rosemary terpenoid, CSOL, as a stem cell targeting natural alternative. With regard to the cancer stem cell-targeted efficacy of natural products, it is noteworthy that several mechanistically distinct natural products have documented efficacy against drug resistant stem cell population. For example, the vitamin A derivative, all-trans retinoic acid (ATRA), inhibits gastric cancer stem cell growth via inhibiting CD44, aldehyde dehydrogenase-1 (ALDH1), Kruppel-like factor-4 (KLF-4) and sex determining region Y-box-2 (SOX-2) expression (24). Sulphoraphane present in broccoli inhibits tumor spheroid formation and ALDH-1 expression in pancreatic and prostate cancer stem cells (25), inhibits NANOG, ALDH-1, Wnt-3 and Notch expression in triple-negative breast cancer stem cells (26), and benzyl isothiocyanate present in cruciferous vegetables inhibits breast cancer stem cells via upregulation of KLF-4-p21 axis (27). The inhibition of established stem cell markers provides potential mechanistic leads for the stem cell-targeted efficacy of natural products.

In addition to natural phytochemicals, nutritional herbs may represent testable alternatives for therapy resistant breast cancer. Herbal aqueous extracts are extensively used in traditional Chinese medicine for a variety of health issues in women, including cancer (28). Non-fractionated aqueous extracts from Chinese nutritional herbs, simulating patient consumption, exhibit anti-proliferative and pro-apoptotic effects in cellular models for molecular subtypes for clinical breast cancer. In the MCF-7 model for the luminal A subtype, Epimedium grandiflorum extract inhibits cancer growth via altering estrogen metabolism and generating anti-proliferative metabolite 2-hydroxyestrone (29). In the MCF-7 ${ }^{\text {AROM }}$ model for aromatase-expressing post-menopausal breast cancer, Taheebo-NFD-Marugoto (TNM), an extract from the Tabebuia avellanedae tree, exhibits anti-proliferative effects via inhibition of estrogen regulated genes and pro-apoptotic effects via increase in pro-apoptotic caspase 3/7 activity and 
upregulation of BAX gene. Additionally, TNM exerts superior inhibitory effects on aromatase activity than clinical aromatase inhibitors (30). In the MDA-MB-231 model for triple-negative breast cancer, Cornus officinalis extract induces anti-proliferative and pro-apoptotic effects via the inhibition of cyclin D1 and $\mathrm{pRB}$, and via the upregulation of caspase-3/7 activity and BAX expression, respectively (31). Collectively, these data provide mechanistic leads for the efficacy of nutritional herbs on models for breast cancer subtypes, and thereby, provide a rationale for investigations on developed stem cell models. It is also notable that the stem cell-specific transcription factors, OCT-4, SOX-2 and NANOG, represent markers for poor survival in HER-2-positive clinical breast cancer (32).

\section{Conclusions and future prospects}

The data reviewed herein lead to the conclusion that the cellular model for the HER-2-enriched breast cancer subtype in general and drug-resistant stem cell model in particular, provide valuable experimental approaches for identifying natural phytochemicals as testable alternatives for treatment of chemotherapy therapy resistant breast cancer.

Human tissue-derived cellular models represent valuable experimental approaches to reduce preclinical data extrapolation for their clinical translatability. However, to further enhance clinical translatability, future investigations utilizing patient derived ex vivo breast cancer organoid models $(33,34)$ are likely to provide valuable clinically translatable data on stem cell-targeting natural products.

\section{Acknowledgements}

The author gratefully acknowledges productive collaboration and active participation of former colleagues in the research program entitled 'Cellular models for molecular subtypes of clinical breast cancer: Mechanistic approaches for lead compound efficacy'.

\section{Funding}

The current research program has been funded in the past by extra-mural grant support from the US National Cancer Institute (NCI) FIRST Award (grant no. CA 44741), NCI Program Project Grant (grant no. PO1 CA 2950, and US Department of Defense Breast Cancer Research Program IDEA Award (grant no. DAMD-17-94-J-4208).

\section{Availability of data and materials}

The data sets used and/or analyzed during the current study are available from the author on reasonable request.

\section{Author's contribution}

The author NT contributed towards study conception, experimental design and prepared the manuscript.

\section{Ethics approval and consent to participate}

Not applicable.

\section{Patient consent for publication}

Not applicable.

\section{Competing interests}

The author declares that there are no competing interests.

\section{References}

1. Sorlie T, Perou CM, Tibshirani R, Aas T, Geisler S, Johnsen H, Hastie T, Eisen MB, Van de Rijn M, Jeffrey SS, et al: Gene expression patterns of breast carcinomas distinguish tumor subclasses with clinical implications. Proc Natl Acad Sci 98: 10869-10874, 2001.

2. Johnston SRD and Dowsett M: Aromatase inhibitors for breast cancer: Lessons from the laboratory. Nat Rev Cancer 3: 821-831, 2003.

3. Baselga $\mathbf{J}$ and Swain SM: Novel anti-cancer targets: Revisiting ERBB2 and discovering ERBB3. Nat Rev Cancer 9: 463-475, 2009.

4. Dean M, Fojo T and Bates S: Tumor stem cells and drug resistance. Nat Rev Cancer 5: 275-284, 2005.

5. Neve RM, Chin K, Fridlyand J, Yeh J, Baehner FL, Fevr T, Clark L, Bayani N, Coppe JP, Tong F, et al: A collection of breast cancer cell lines for the study of functionally distinct cancer subtypes. Cell 10: 515-527, 2006.

6. Subik K, Lee JF, Baxter L, Strezepel T, Costello D, Crowley P, Xing L, Hung MC, and Bonfiglio T: Expression patterns of ER, PR, HER-2, CK5/6, Ki-67and AR by immune-histochemical analysis in breast cancer cell lines. Breast Cancer 4: 35-41, 2010.

7. Gupta A, Mehta R, Alimirah F, Peng X, Murillo G, Weihle R and Mehta RG: Efficacy and mechanism of action Proellex, an anti-progestin in aromatase over-expressing and letrozole resistant T47D breast cancer cells. J Steroid Biochem Mol Biol 133: 30-42, 2013.

8. Hole S, Pedersen AM, Hansen SK, Lundqvist J, Yde CW and Lykkesfeldt AE: A new cell culture model for aromatase resistant breast cancer shows sensitivity to fluvestrant treatment and cross resistance between letrozole and exemestane. Int J Oncol 46: 1481-1490, 2015.

9. Dey P, Rathod M and De A: Targeting stem cells in the realm of drug-resistant breast cancer. Breast Cancer (Dove Med Press) 11: 115-135, 2019.

10. Stampfer MR and Bartley JC: Induction of transformation and continuous cell lines from normal human mammary epithelial cell lines after exposure to benzo[a]pyrene. Proc Natl. Acad Sci USA 82: 2394-2398, 1985.

11. Zhai WF, Beittenmiller H, Wang B, Gould MN, Oakley C, Esselman WJ and Welch CW: Increased expression of protein tyrosine phosphatases in human breast epithelial cells neoplastically transformed by the neu oncogene. Cancer Res 53: 2272-2278, 1993.

12. Telang N: Targeting drug resistant stem cells in a human epidermal growth factor receptor-2-enriched breast cancer model. World Acad Sci J 1: 86-91, 2019.

13. Katdare M, Osborne M and Telang NT: Soy isoflavone genestein modulates cell cycle progression and induces apoptosis in HER-2 oncogene expressing human breast epithelial cells. Int J Oncol 21: 809-815, 2002.

14. Telang NT, Katdare M, Bradlow HL, Osborne MP and Fishman J: Inhibition of proliferation and modulation of estradiol metabolism: Novel mechanisms for breast cancer prevention by the phytochemical indole-3-carbinol. Proc Soc Exp Biol Med 216: 246-252, 1997.

15. Katdare M, Jinno H, Osborne MP and Telang NT: Negative growth regulation of oncogene-transformed human breast epithelial cells by phytochemicals: Role of apoptosis. Ann NY Acad Sci 889: 247-252, 1999.

16. Telang N: Anti-proliferative and pro-apoptotic effects of rosemary and constituent terpenoids in a model for HER-2-enriched molecular subtype of clinical breast cancer. Oncol Letts 16: 5489-5497, 2018.

17. Subbaramaiah K, Cole PA and Dannenberg AJ: Retinoids and carnosol suppress cyclooxygenase-2 transcription by CREB-binding protein/p300 dependent- and-independent mechanisms. Cancer Res 62: 2522-2530, 2002.

18. Rahman KM, Li Y and Sarkar FH: Inactivation of Akt and NF-kappaB play important roles during indole-3-carbinol-induced apoptosis in breast cancer cells. Nutr Cancer 48: 84-94, 2004. 
19. Schroder L, Marahrens P, Koch GJ, Heidegger H, Vilsmeier T, Phan-Brehm T, Hofmann S, Mahner S, Jeschke U and Richter DU: Effects of green tea, matcha tea and their components epigallocatechin gallate and quercetin on MCF-7 and MDA-MB-231 breast carcinoma cells. Oncol Rep 41: 387-396, 2019.

20. Kabala-Dzik A, Rzepecka-Stojko A, Kubina R, Iriti M, Wojtyczka RD, Buszman E and Stojko J: Flavonoids, bioactive components of Propolis, exhibit cytotoxic activity and induce cell cycle arrest and apoptosis in human breast cancer cells MDA-MB-231 and MCF-7-a comparative study. Cell Mol Biol (Noisy-le-Grand) 64: 1-10, 2018.

21. Al-Daheri Y, Attoub S, Ramadan G, Arafat K, Bajbouj K Karuvantevida N, AbuQamar S, Eid A and Iratni R: Carnosol induces ROS-mediated beclin1-independent autophagy and apoptosis in triple negative breast cancer. PLoS One 9: e109630, 2014.

22. Rusnak DW, Lackey K, Affleck K, Wood ER, Alligood KJ Rhodes N, Keith BR, Murray DM, Knight WB, Mullin RJ and Gilmer TM: The effects of the novel, reversible epidermal growth factor/ErB2 tyrosine kinase inhibitor, GW2016, on the growth of human normal and tumor-derived cell lines. Mol Cancer Ther 1 : 85-94, 2001.

23. Nahta R, Yuan LXH, Du Y and Esteva FJ: Lapatinib induces apoptosis in trastuzumab-resistant breast cancer cells: Effect on insulin-like growth factor I signaling. Mol Cancer Ther 6 : 667-674, 2007.

24. Nguyen PH, Giraud J, Staedel C, Chambonnier L, Dubus P, Chevret E, Boeuf H, Gauthereau X, Rousseau B, Fevre M, et al: All-trans retinoic acid targets gastric cancer stem cells and inhibits patient-derived gastric carcinoma tumor growth. Oncogene 35: 5619-5628, 2016

25. Kallifatidis G, Labsch S, Rausch V, Mattern J, Galdkich J, Moldenhauer D, Buchler MW, Salinikov AV and Herr I: Sulphoraphane increases drug-mediated cytotoxicity toward cancer stem-like cells of pancreas and prostate. Mol Cancer Ther 19: 188-195, 2011.

26. Castro NP, Rangel MC, Merchant AS, MacKinnon G, Cuttitta F, Salomon DA and Kim YS: Sulphoraphane suppresses the growth of triple negative breast cancer stem-like cells in vitro and in vivo. Cancer Prev Res (Phila) 12: 147-158, 2019.
27. Kim SH and Singh SV: Role of Kruppel-like factor-4/p21 ${ }^{\mathrm{CIP} 1}$ axis in breast cancer stem-like cell inhibition by benzyl isothiocyanate. Cancer Prev Res (Phila) 12: 125-134, 2019.

28. Ye I, Jia Y, Ji KE, Sanders AJ, Xue K, Ji J, Mason MD and Jiang WG: Traditional Chinese medicine in the prevention and treatment of breast cancer and cancer metastasis. Oncol Lett 10: 1240-1250, 2015

29. Telang NT, Li G, Katdare M, Sepkovic DW, Bradlow HL and Wong GY: The nutritional herb Epimedium grandiflorum inhibits the growth in a model for the Luminal A molecular subtype of breast cancer. Oncol Letts 13: 2477-2482, 2017.

30. Telang N, Nair HB and Wong GYC: Growth inhibitory efficacy and anti-aromatase activity of Tabebuia avellanedae in a model for post-menopausal Luminal A breast cancer. Biomed Rep 11: 222-229, 2019.

31. Telang NT, Nair HB and Wong GYC: Growth inhibitory efficacy of Cornus officinalis in a cell culture model for triple negative breast cancer. Oncol Lett 17: 5261-5266, 2019.

32. Yang F, Zhang J and Yang H: OCT4, SOX2 and NANOG positive expression correlates with poor differentiation, advanced disease stages and worse overall survival in HER-2 $2^{+}$breast cancer patients. Onco Targets Ther 11: 7873-7881, 2018.

33. Bruna A, Rouda OM Greenwood A, Batra AS, Callari M, Batra RN, Pogrebniak K, Sandoval J, Cassidy JW, Tufegdzic-Vidakocic A, et al: A biobank of breast cancer explants with preserved intra-tumor heterogeneity to screen anti-cancer compounds. Cell 167: 260-274.e22, 2016.

34. Sachs N, de Ligt J, Kopper O, Gogola E, Bounova G, Weeber E, Balgobind AV, Wind K, Gracanin A, Begthel $\mathrm{H}$, et al: A living biobank of breast cancer organids captures disease heterogeneity. Cell 172: 373-386.e10, 2018.

This work is licensed under a Creative Commons Attribution-NonCommercial-NoDerivatives 4.0 International (CC BY-NC-ND 4.0) License. 